\title{
Ocular Signs and Ocular Comorbidities in Monoclonal Gammopathy: Analysis of 80 Subjects
}

\author{
Kitti Kormányos $\mathbb{D}^{1,},{ }^{1,2}$ Klaudia Kovács, ${ }^{1}$ Orsolya Németh ${ }^{(D)},{ }^{3}$ Gábor Tóth ${ }^{(D)}{ }^{1}$ \\ Gábor László Sándor, ${ }^{1}$ Anita Csorba, ${ }^{1}$ Cecília Nóra Czakó, ${ }^{1}$ Achim Langenbucher $\mathbb{D},{ }^{4}$ \\ Zoltán Zsolt Nagy $\mathbb{D}^{1}$, Gergely Varga $\mathbb{D}^{5},{ }^{5}$ László Gopcsa, ${ }^{6}$ Gábor Mikala $\mathbb{D}^{6}{ }^{6}$ \\ and Nóra Szentmáry $\mathbb{B D}^{1,7}$
}

\author{
${ }^{1}$ Semmelweis University, Department of Ophthalmology, Budapest, Hungary \\ ${ }^{2}$ Medical Centre, Hungarian Defence Forces, Department of Ophthalmology, Budapest, Hungary \\ ${ }^{3}$ Markusovszky University Teaching Hospital, Department of Ophthalmology, Szombathely, Hungary \\ ${ }^{4}$ Experimental Ophthalmology, Saarland University, Homburg, Saarland, Germany \\ ${ }^{5} 3^{\text {rd }}$ Department of Internal Medicine and Haematology, Semmelweis University, Budapest, Hungary \\ ${ }^{6}$ South-Pest Central Hospital-National Institute for Hematology and Infectious Diseases, \\ Department of Hematology and Stem Cell-Transplantation, Budapest, Hungary \\ ${ }^{7}$ Dr. Rolf M. Schwiete Center for Limbal Stem Cell and Congenital Aniridia Research, Saarland University, \\ Homburg, Saarland, Germany
}

Correspondence should be addressed to Kitti Kormányos; kitti0820@gmail.com

Received 4 March 2021; Revised 29 May 2021; Accepted 10 June 2021; Published 19 June 2021

Academic Editor: Dirk Sandner

Copyright $(2021$ Kitti Kormányos et al. This is an open access article distributed under the Creative Commons Attribution License, which permits unrestricted use, distribution, and reproduction in any medium, provided the original work is properly cited.

\begin{abstract}
Purpose. To examine the ocular signs of monoclonal gammopathy and to evaluate ocular comorbidities in subjects with monoclonal gammopathy. Patients and Methods. We analyzed patients from two large referral hematology centers in Budapest, diagnosed and/or treated with monoclonal gammopathy between 1997 and 2020. As a control group, randomly selected individuals of the same age group, without hematological disease, have been included. There were 160 eyes of 80 patients (38.75\% males; age $67.61 \pm 10.48$ (range: $38-85$ ) years) with monoclonal gammopathy and 86 eyes of 43 control subjects ( $32.56 \%$ males; age $62.44 \pm 11.89$ (range $37-86$ ) years). The hematological diagnosis was MGUS in 9 (11.25\%), multiple myeloma in 61 (76.25\%), smoldering myeloma in $6(7.50 \%)$, and amyloidosis or Waldenström macroglobulinemia in 2 cases $(2.50 \%-2.50 \%)$. Before detailed ophthalmic examination with fundoscopy, 42 subjects with gammopathy (52.50\%) and all controls filled the Ocular Surface Disease Index (OSDI) questionnaire. Results. The OSDI score and best-corrected visual acuity (BCVA) were significantly worse in subjects with monoclonal gammopathy than in controls $(p=0.02 ; p=0.0005)$. Among gammopathy subjects, we observed potential corneal immunoglobulin deposition in 6 eyes of $4(3.75 \%)$ patients. Ocular surface disease $(p=0.0001)$, posterior cortical cataract $(p=0.01)$, and cataract $(p=0.0001)$ were significantly more common among gammopathy subjects than in controls $\left(\chi^{2}\right.$ test). Conclusions. Ocular surface disease and cataract are more common, and BCVA is worse in patients with monoclonal gammopathy than in age-matched controls. Therefore, and due to the potential ocular signs and comorbidities of monoclonal gammopathy, we suggest a regular, yearly ophthalmic checkup of these patients to improve their quality of life.
\end{abstract}

\section{Introduction}

The spectrum of monoclonal gammopathies spans clonal plasma cell diseases from monoclonal gammopathy of undetermined significance (MGUS), solitary plasmacytoma,
Waldenström macroglobulinemia, and asymptomatic or symptomatic multiple myeloma to plasma cell leukemia [1-3]. MGUS is considered a premalignant state that has three different types with IgM MGUS, non-IgM MGUS (IgA- and IgG-MGUS), and light chain MGUS. All forms of 
MGUS can cause amyloidosis, a special sort of light chain deposition disease, or non-Hodgkin lymphoma, which are important differential diagnostic entities [4].

Diagnostic criteria for MGUS according to the 2015 recommendation of the International Myeloma Working Group are bone marrow plasma cell content less than $10 \%$, less than $3 \mathrm{~g} / \mathrm{dL}$ of monoclonal protein level (M-protein) in the serum, and no indication of organ disruption, that is characteristic for malignant B-cell disease (no hypercalcemia, renal failure, anemia, or bone changes) [5-7]. However, with IgG-type M-protein of less than $1.5 \mathrm{~g} / \mathrm{dL}$, bone marrow biopsy is often defered if the patient is asymptomatic. The prevalence of MGUS increases with age from $1.7 \%$ in individuals with $50-59$ years of age to $6.6 \%$ in individuals with $>80$ years of age (Kyle et al. 2006) [8].

In monoclonal gammopathy, monoclonal protein deposition has been described in different organs in the literature [9]. In multiple myeloma, kidneys are involved up to $40 \%$ [10], and unexplained polyneuropathy is present in $5-10 \%$ [11-13]. There may also be insulin autoimmune syndrome [14], infiltrative or restrictive cardiomyopathy [15], gastrointestinal system involvement [16], and infiltrative or "paraneoplastic"-like skin disease [17].

As ocular signs of gammopathy, corneal deposits, conjunctival deposits, acute/chronic uveitis [18, 19], maculopathy, foveolar drusen [20-22], Doyne retinal dystrophy [23], central retinal artery or vein occlusion [24], myositis, and proptosis [25] have been described.

Corneal deposits associated with monoclonal gammopathy (or paraproteinaemia) have been first described in the 1900s as chameleon-like changes $[26,27]$. These are mostly bilateral, grey-white, yellowish, grey-brown, polychromatic, or crystal-like changes in any layer of the cornea. These may be either diffuse or focal, central or peripheral deposits [5]. As these corneal deposits in MGUS may appear in countless forms, they have been termed "chameleon-like" corneal depositions by Lisch and his coworkers. They created a uniform and internationally accepted nomenclature in 2012, which distinguished 5 different types of immunotactoid keratopathy (ITK): crystalline-like ITK, lattice-like ITK, peripheral granular-like ITK, peripheral band-like ITK, and peripheral patch-like ITK. Later in 2016, they expanded the classification system to 11 distinct forms of MGUSinduced paraproteinemic keratopathy [27].

However, data on the occurrence of ocular signs of monoclonal gammopathy and on ocular comorbidities are not yet described. We aimed to determine the ocular signs of monoclonal gammopathy and the ocular comorbidities in subjects with monoclonal gammopathy.

\section{Patients and Methods}

In our perspective, it is a cross-sectional study in which we analyzed patients of the Department of Hematology and Stem Cell-Transplantation of the South-Pest Center Hospital, National Institute for Hematology and Infectious Disease, Budapest, Hungary, and the 3rd Department of Internal Medicine, Semmelweis University, Budapest, Hungary, diagnosed and treated with monoclonal gammopathy between
1997 and 2020. As a control group, randomly selected individuals of the same age group, without hematological disease, have been included. The local ethics committee gave permission to our study (OGYÉI/50115/2018). Participation in this study has been voluntary, and written informed consent was obtained from all participants.

In our study, we analyzed altogether 246 eyes of 123 patients (age $66.2 \pm 11.11$ years). There were 160 eyes of 80 patients (38.75\% males; age $67.61 \pm 10.48$ (range: $38-85$ ) years) with monoclonal gammopathy. Eighty-six eyes of 43 subjects $(32.56 \%$ males; age $62.44 \pm 11.89$ (range: $37-86$ ) years) have been analyzed as controls. The age of the patients in the gammopathy and control groups did not differ significantly $(p=0.17)$ (Table 1$)$.

In patients with established hematological diagnosis, the time of the hematological diagnosis was in one case (1.25\%) within 1 year, in $36(45.00 \%)$ cases within 5 years, in 29 (36.25\%) cases within 5-10 years, and in 14 (17.50\%) cases more than 10 years ago. The hematological diagnosis was MGUS in $9(11.25 \%)$, multiple myeloma in 61 (76.25\%), smoldering myeloma in 6 (7.50\%), and amyloidosis or Waldenström macroglobulinemia in 2 cases $(2.50 \%)$.

With respect to immunoglobulin heavy chains, there was an increased IgG level in 52 individuals (65.00\%), an increased IgA level in 20 (25.00\%), an increased IgM level in 4 (5.00\%), and an increased IgD level in 1 case (1.25\%). Considering light chains, kappa chain in 49 subjects $(61.25 \%)$, and lambda chain in 31 patients $(38.75 \%)$ have been verified, and in 3 cases (3.75\%), heavy chain production was not detectable.

With respect to organ dysfunction in gammopathy patients, osteolytic lesions have been previously described in 39 subjects (48.75\%), renal involvement in 19 patients (23.75\%), polyneuropathy in 6 cases $(7.50 \%)$, spinal cord involvement in 3 cases (3.75\%), and liver involvement and thrombosis of the upper limb in 2 cases (2.5\%), respectively. In single cases, infiltration of the nervus medianus and skin lesions $(1.25 \%)$ were identified. There was no renal involvement in $4(5.00 \%)$ and no other organ involvement in 8 $(10.00 \%)$ subjects in the hematological disease history. 36 subjects $(45.00 \%)$ had previous autologous stem cell transplantation, and 65 subjects $(81.25 \%)$ received chemotherapy, according to their hematological disease history.

In the gammopathy group, there was hypertension in 59 (73.75\%), type 2 diabetes mellitus in $15(18.75 \%)$, cardiac arrhythmia in 10 (12.50\%), gastro-oesophageal reflux in 9 (11.25\%), previous myocardial infarction in $4(5.00 \%)$, deep vein thrombosis in $4(5.00 \%)$, stroke in $3(3.75 \%)$, benign prostate hyperplasia in $3(3.75 \%)$, prostate cancer in 3 (3.75\%), cervix cancer in $3(3.75 \%)$, hyperthyroidism in 3 (3.75\%), asthma bronchiale in $2(2.50 \%)$, breast cancer in 2 (2.50\%), Raynaud's syndrome in $2(2.50 \%)$, rheumatoid arthritis in $2(2.50 \%)$, hypothyroidism in $2(2.50 \%)$, endometriosis in $1(1.25 \%)$, pulmonary embolism in $1(1.25 \%)$, systemic lupus erythematosus in $1(1.25 \%)$, colon cancer in 1 (1.25\%), endometrial cancer in $1(1.25 \%)$, and squamous cell skin cancer in $1(1.25 \%)$ subject.

In the control group, there was hypertension in 16 (37.21\%), type 2 diabetes in $6(13.95 \%)$, atrial fibrillation in 2 
TABle 1: Age, gender, Ocular Surface Disease Index (OSDI) score, best-corrected visual acuity (BCVA) in control subjects and in patients with monoclonal gammopathy (MGUS).

\begin{tabular}{lcccc}
\hline- & $\begin{array}{c}\text { Age (years) } \\
(\text { mean } \pm \text { SD (minimum- } \\
\text { maximum) })\end{array}$ & $\begin{array}{c}\text { Males } \\
(n(\%))\end{array}$ & $\begin{array}{c}\text { OSDI (mean } \pm \text { SD (minimum- } \\
\text { maximum) })\end{array}$ & $\begin{array}{c}\text { BCVA (mean } \pm \text { SD (minimum- } \\
\text { maximum) })\end{array}$ \\
\hline Control & $62.44 \pm 11.89(37-86)$ & $\begin{array}{c}14 \\
(32.56 \%)\end{array}$ & $12.66 \pm 11.00(0-50)$ & $0.94 \pm 0.16(0.06-1)$ \\
MGUS & $67.61 \pm 10.48(38-85)$ & $31(38.75 \%)$ & $21.51 \pm 18.03(0-65.9)$ & $0.82 \pm 0.26(0.01-1)$ \\
$P$ value & 0.17 & 0.67 & $\mathbf{0 . 0 2}$ & $\mathbf{0 . 0 0 0 5}$ \\
\hline
\end{tabular}

$P$ values refer to results of Mann-Whitney $U$-test (age, OSDI, and BCVA) and of $\chi^{2}$ test with Yates correction (males) (comparison between both groups). Significant values are in bold.

(4.65\%), gastro-oesophageal reflux in $1(2.32 \%)$, prostate cancer in $1(2.32 \%)$, and colon cancer in $1(2.32 \%)$ subject in history, respectively.

Before the ophthalmic examination, 42 subjects with gammopathy $(52.50 \%)$ and all control subjects filled the Ocular Surface Disease Index (OSDI) questionnaire (score ranges were designated as normal (0-12), mild (13-22), moderate (23-32), or severe (33-100) ocular surface disease), and for all patients, ophthalmic medical history has been taken. Ophthalmic examination included refractometry, visual acuity test (best-corrected visual acuity), Goldmann applanation tonometry, and slit-lamp examination following dilation of the pupil. In the case of retinal disease, optical coherence tomography (AngioVue OCTA, RTVue XR Avanti, OptoVue, Fremont CA, USA) has also been performed.

For statistical analysis of the data, the Mann-Whitney $U$ test and $\chi^{2}$ test have been used.

\section{Results}

Ophthalmic history and results of the ophthalmic examination in patients with monoclonal gammopathy and in control subjects are summarized in Tables 2 and 3.

In the ophthalmic history of subjects with monoclonal gammopathy, there was no history of ocular disease in 66 $(41.25 \%)$, and there was dry eye disease in $64(40.00 \%)$, cataract in $27(16.88 \%)$, previous cataract surgery in 20 $(12.50 \%)$, glaucoma in $12(7.50 \%)$, posterior cortical cataract in $4(2.50 \%)$, and previous penetrating keratoplasty in 2 eyes $(1.25 \%)$. In the subgroup of the 8 subjects with MGUS (16 eyes, without previous systemic corticosteroid treatment), there was a cataract in $14(77.77 \%)$ and posterior cortical cataract in $4(22.23 \%)$ eyes. None of them had previous cataract surgery.

In the ophthalmic history of controls, there was no history of ocular disease in 22 (25.58\%), and there was dry eye disease in 17 (19.77\%), previous cataract surgery in 12 (13.95\%), cataract in $12(13.95 \%)$, glaucoma in $4(4.65 \%)$ and posterior cortical cataract in $1(1.16 \%)$ eyes.

In ophthalmic history, the proportion of subjects with dry eye disease was significantly higher in monoclonal gammopathy subjects as in controls $(p=0.002)$.

Using the OSDI questionnaire, among patients with hematological diagnosis, there were 14 (33.33\%) subjects with normal ocular surface, 11 (26.19\%) had mild, 6 (14.29\%) had moderate, and 11 (26.19\%) had severe ocular surface disease.
Among the control subjects, there were 27 subjects $(62.79 \%)$ with normal ocular surface, 7 subjects $(16.28 \%)$ with mild, 7 (16.28\%) with moderate, and 2 (4.65\%) with severe ocular surface disease. OSDI score was significantly worse in subjects with monoclonal gammopathy than in controls $(p=0.02)$.

In patients with hematological diagnosis, best-corrected visual acuity (BCVA) was $0.82 \pm 0.26$ (logMAR $0.1 \pm 0.26$ ), and in controls, it was $0.94 \pm 0.16$ (logMAR $0.1 \pm 0.16)$. BCVA was significantly worse in subjects with gammopathy than in controls at the examination timepoint $(p=0.0005)$.

Among patients with gammopathy, we found 89 (55.63\%) eyes of 53 patients with 1.0 (0.0 logMAR) and 66 eyes $(41.25 \%)$ of 42 patients between 0.2 and $0.9(0.1-0.7$ $\operatorname{logMAR})$ BCVA. Five (3.13\%) eyes of 5 patients were not able to read the chart. Between controls, in the majority of the subjects, 68 (79.07\%) eyes had BCVA 1.0 (0.0 logMAR), $12(13.95 \%)$ eyes of 10 patients had BCVA 0.8-0.9 (0.1 logMAR), 5 (5.81\%) eyes of 5 patients had BCVA between 0.2 and 0.7 (0.2-0.5 logMAR), and 1 (1.16\%) eye of 1 patient was not able to read the chart.

Among ophthalmological findings of gammopathy subjects, there was ocular surface disease in 56 (66.67\%), cataract in 86 (53.75\%), Meibomian gland dysfunction in 30 (18.75\%), no ophthalmic disease in 22 (13.75\%), posterior cortical cataract in $21(13.13 \%)$, previous cataract surgery in $20(12.50 \%)$, macular or retinal drusen in $18(11.25 \%)$, chronic blepharitis in $16(10.00 \%)$, glaucoma in $12(7.50 \%)$, age-related macular degeneration in $12(7.50 \%)$, epiretinal membrane in $10(6.25 \%)$, Fuchs dystrophy in $8(5.00 \%)$, peripheral retinal degeneration in $7(4.38 \%)$, corneal immunoglobulin deposition in $6(3.75 \%)$, diabetic retinopathy in $4(2.50 \%)$, amblyopia in $3(1.88 \%)$, macular hole in 1 $(0.63 \%)$, central retinal artery occlusion in $1(0.63 \%)$, branch retinal vein occlusion in $1(0.63 \%)$, choroidal nevus in 1 $(0.63 \%)$, and retinal scar in $1(0.63 \%)$ eye.

Among gammopathy subjects, we observed potential corneal immunoglobulin deposition in 6 eyes of $4(7.50 \%)$ patients (Figure 1). One of these patients underwent penetrating keratoplasty (PKP) prior to enrollment (Figure 1(f)). These corneal deposits have been observed in both eyes in 2 patients (Figures $1(\mathrm{a})-1(\mathrm{~d})$ ) and in 1 eye in 2 patients (Figures 1(e) and 1(f)). The diagnosis was monoclonal gammopathy with ocular significance (MGOS) in 1 (Figures 1(a) and 1(b)) and multiple myeloma in 3 (Figures 1(c)-1(f)) of these subjects. 
TABLE 2: Ophthalmic diagnosis in ophthalmic history of control subjects and in patients with monoclonal gammopathy (MG).

\begin{tabular}{|c|c|c|c|}
\hline Ophthalmic diagnosis & Control $(n=86)$ & MG $(n=160)$ & $P$ values \\
\hline Dry eye disease & $17(19.77 \%)$ & $64(40.00 \%)$ & 0.002 \\
\hline Penetrating keratoplasty & 0 & $2(1.25 \%)$ & - \\
\hline Glaucoma & $4(4.65 \%)$ & $12(7.50 \%)$ & 0.55 \\
\hline Previous cataract surgery & $12(13.95 \%)$ & $20(12.50 \%)$ & 0.90 \\
\hline Cataract & $12(13.95 \%)$ & $27(16.88 \%)$ & 0.54 \\
\hline Posterior cortical cataract & $1(1.16 \%)$ & $4(2.50 \%)$ & 0.47 \\
\hline Without previous ophthalmic diagnosis & $22(25.58 \%)$ & $66(41.25 \%)$ & 0.01 \\
\hline Total & $86(100 \%)$ & $160(100 \%)$ & - \\
\hline
\end{tabular}

$P$ values refer to results of $\chi^{2}$ test with Yates correction (comparison between both groups). Significant values are in bold. With "0" value, $\chi^{2}$ test could not be calculated.

TABLE 3: Ophthalmological findings in control subjects (86 eyes) and in patients with monoclonal gammopathy (MG) (160 eyes, except for ocular surface disease, as OSDI questionnaire has only been filled through 42 subjects).

\begin{tabular}{|c|c|c|c|}
\hline Ophthalmic diagnosis & Control $(n=86)$ & MG $(n=160)$ & $P$ values \\
\hline Ocular surface disease (OSDI) & $32(37.21 \%)(n=86)$ & $56(66.67 \%)(n=84)$ & 0.0001 \\
\hline Meibomian gland dysfunction & $10(11.63 \%)$ & $30(18.75 \%)$ & 0.20 \\
\hline Chronic blepharitis & $16(18.60 \%)$ & $16(10.00 \%)$ & 0.08 \\
\hline Corneal scars and degenerations & $5(5.81 \%)$ & $21(13.13 \%)$ & 0.07 \\
\hline Corneal immunglobulin deposition & 0 & $6(3.75 \%)$ & - \\
\hline Fuchs dystrophy & $2(2.33 \%)$ & $8(5.00 \%)$ & 0.50 \\
\hline Glaucoma & $4(4.65 \%)$ & $12(7.50 \%)$ & 0.55 \\
\hline Previous cataract surgery & $12(13.95 \%)$ & $20(12.50 \%)$ & 0.90 \\
\hline Cataract & $17(19.76 \%)$ & $86(53.75 \%)$ & 0.0001 \\
\hline Posterior cortical cataract & $3(3.49 \%)$ & $21(13.13 \%)$ & 0.01 \\
\hline Epiretinal membrane & $2(2.33 \%)$ & $10(6.25 \%)$ & 0.29 \\
\hline Age-related macular degeneration & 0 & $12(7.50 \%)$ & - \\
\hline Macular or retinal drusen & $16(18.60 \%)$ & $18(11.25 \%)$ & 0.16 \\
\hline Macular hole & 0 & $1(0.63 \%)$ & - \\
\hline Diabetic retinopathy & $4(4.65 \%)$ & $4(2.50 \%)$ & 0.59 \\
\hline Peripheral retinal degeneration & $4(4.65 \%)$ & $7(4.38 \%)$ & 0.82 \\
\hline Central retinal artery occlusion & 0 & $1(0.63 \%)$ & - \\
\hline Branch retinal vein occlusion & 0 & $1(0.63 \%)$ & - \\
\hline Choroideal naevus & 0 & $1(0.63 \%)$ & - \\
\hline Retinal scar after chorioretinitis & 0 & $1(0.63 \%)$ & - \\
\hline Ambyopia & $1(1.16 \%)$ & $3(1.88 \%)$ & 0.93 \\
\hline Without ophthalmic disease & $14(16.28 \%)$ & $22(13.75 \%)$ & 0.72 \\
\hline Total & $86(100 \%)$ & $160(100 \%)$ & - \\
\hline
\end{tabular}

$P$ values refer to results of $\chi^{2}$ test with Yates correction (comparison between both groups). Significant values are in bold. With "0" value, $\chi^{2}$ test could not be calculated. OSDI: Ocular Surface Disease Index.

In gammopathy subjects, in the group of corneal scars and degenerations, there was arcus senilis in $8(5.00 \%)$, crocodile shagreen in $6(3.75 \%)$, iron line and corneal scar due to previous corneal foreign body removal in $5(3.13 \%)$, Salzmann nodular degeneration in $1(0.63 \%)$ and stromal scar and calcification due to previous stromal herpes keratitis in $1(0.63 \%)$ eye.

Between ophthalmological findings of control subjects, there was ocular surface disease in $32(37.21 \%)$, cataract in 17 $(19.77 \%)$, macular or retinal drusen in $16(18.60 \%)$, chronic blepharitis in $16(18.60 \%)$, no ophthalmic disease in 14 $(16.28 \%)$, previous cataract surgery in 12 (13.95\%), Meibomian gland dysfunction in $10(11.63 \%)$, glaucoma in 4 (4.65\%), diabetic retinopathy in $4(4.65 \%)$, peripheral retinal degeneration in $4(4.65 \%)$, posterior cortical cataract in 3 (3.49\%), Fuchs dystrophy in $2(2.33 \%)$, epiretinal membrane in $2(2.33 \%)$, and amblyopia in $1(1.16 \%)$ eye.
In control subjects, in the group of corneal scars and degeneration, there was arcus senilis in 2 (2.33\%), crocodile shagreen in $2(2.33 \%)$, and iron line and corneal scar due to previous corneal foreign body removal in $1(1.16 \%)$ eye. The proportion of subjects with corneal scars and degenerations in the gammopathy group did not differ from controls $(p=0.07)$.

\section{Discussion}

To the best of our knowledge, this is the first study to analyze ocular signs and ocular comorbidities of monoclonal gammopathy. In Hungary, approximately 350-400 new patients are diagnosed and registered with multiple myeloma yearly and 120-150 autologous bone marrow transplantations are performed due to multiple myeloma [28]. The incidence of MGUS is unknown. Most interestingly, ocular surface disease and cataract are more common, and BCVA and OSDI scores 


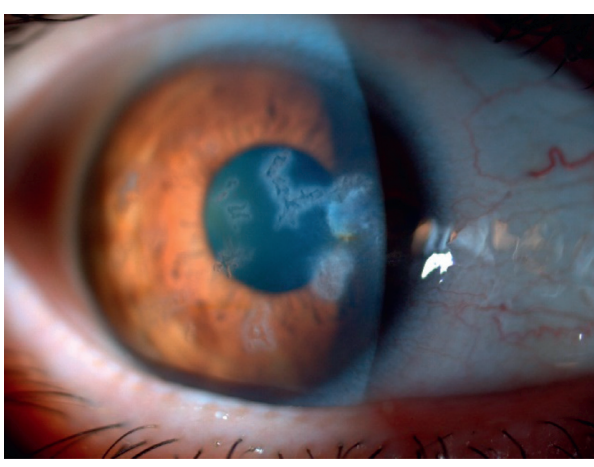

(a)

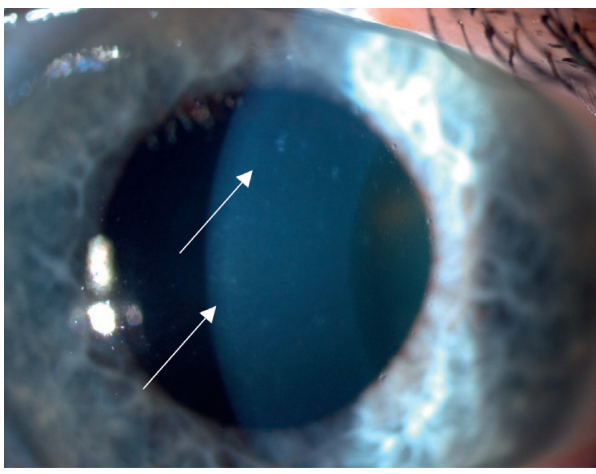

(c)

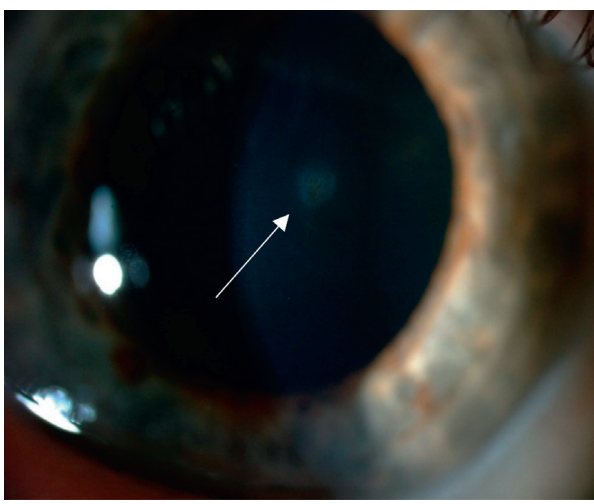

(e)

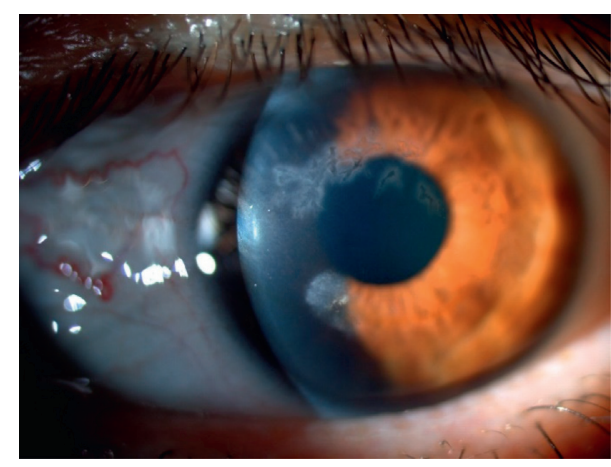

(b)

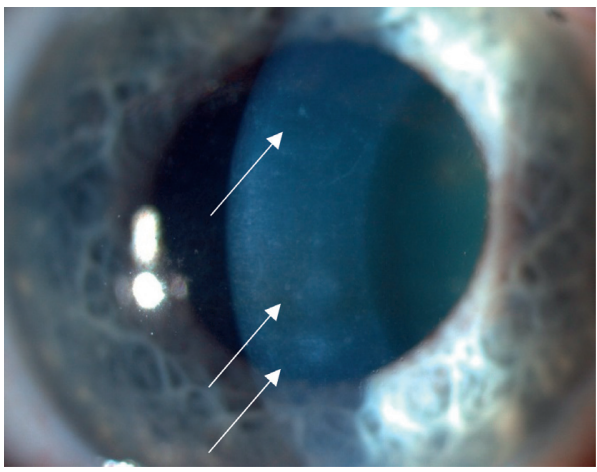

(d)

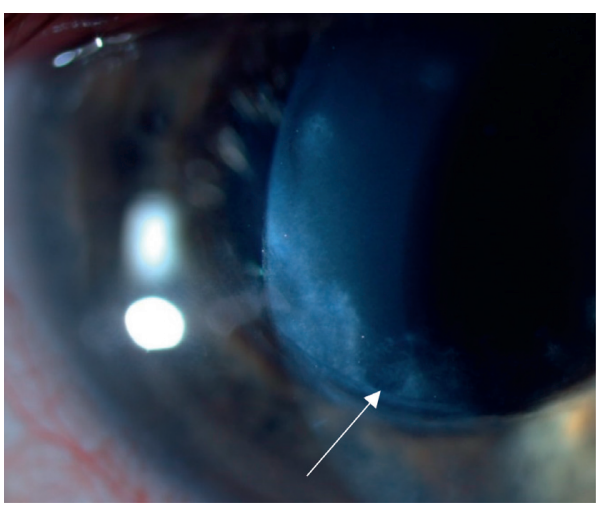

(f)

FIGURE 1: Corneal opacities in six eyes of four patients with monoclonal gammopathy. Sharp-edged, branching predescemetal opacities in both eyes of one patient with monoclonal gammopathy of ocular significance (MGOS) (a, b), sharpe-edged, round or puntual, fine subepithelial opacities in both eyes of one subject with cornea guttata and multiple myeloma (c, d), round stromal opacity in one eye of one subject with multiple myeloma (e), sand-like stromal deposits along the removed penetrating keratoplasty (PKP) running-suture line in one eye of one subject with multiple myeloma (f).

are worse (BCVA lower, OSDI scores higher) in patients with gammopathy than in age-matched controls.

In our analyzed cohort with gammopathy with a mean age of 67.61 years and control subjects with a mean age of 62.44 years, the prevalence of ocular surface disease using the OSDI questionnaire was $66.67 \%$ and $37.21 \%$, respectively. In the literature, the prevalence of dry eye disease in subjects older than 50 years was described to be $5-34 \%[29,30]$, which confirms our results observed in the control subjects. Nevertheless, in patients with monoclonal gammopathy, the OSDI score and prevalence of ocular surface disease was significantly higher than expected. This could be related to the monoclonal gammopathy itself, or to the previous systemic corticosteroid treatment or chemotherapy which the patients underwent (for malignant plasma cell disorder). Dry eye disease has been previously described as a side effect of these systemic treatment forms [31].

Although the percentage of patients with previous cataract surgery did not differ significantly between both groups, the proportion of subjects with unoperated posterior cortical cataract or cataract was significantly higher in subjects with gammopathy (13.13\% vs. $3.49 \%$ and $53.75 \%$ vs. $19.76 \%)$ than in controls $(p=0.0001$ and $p=0.01)$. Similarly to dry eye disease, cataract formation has also been 
associated with systemic corticosteroid treatment (subjects with plasma cell malignancy exhibiting monoclonal gammopathy often receive systemic steroids over months, mostly due to induction therapy before autologous stem cell transplantation) and multiagent chemotherapy, previously [32], but could also be associated with the monoclonal gammopathy itself and the changes in protein metabolism. Chen et al. described cataract prevalence in 6725 subjects older than 50 years $23.1 \%$ [33]. In our study population with monoclonal gammopathy, cataract prevalence was more than two times higher than in our control subjects and nearly two times higher than in the study of Chen et al. In addition, cataract prevalence was also similar in the corticosteroid naive MGUS patient group.

Prevalence of chronic blepharitis was described to be $8.1 \%$ in subjects older than 40 years by Rim et al. [34]. Similarly, there was chronic blepharitis in $10.0 \%$ of gammopathy subjects and its percentage did not differ from our control subjects, or historic data.

The prevalence of Meibomian gland dysfunction was described to be $36 \%$ in subjects with $50-59$ years of age [35]. Interestingly, Meibomian gland dysfunction was rather uncommon with $11.63 \%$ in our control and with $18.75 \%$ in our gammopathy groups, without statistically significant difference.

Epidemiological data show that patients with myeloproliferative neoplasms suffer from an accelerated accumulation of subretinal drusen, and this phenomenon is associated with an increased risk of neovascular age-related macular degeneration (AMD) [36]. Immunoglobulin deposition has also been associated with maculopathy and the appearance of foveolar drusen [20]. Although there was AMD in $7.5 \%$ of our gammopathy subjects and none in our control subjects, the percentage of macular or retinal drusen did not differ between both groups with $11.25 \%$ vs. $18.6 \%$. This needs further analysis.

There are numerous studies in the literature describing corneal deposition in monoclonal gammopathy. Garibaldi et al. [26] in 2004 presented a case report and literature review, summarizing 38 cases with corneal deposition.

In our subjects with monoclonal gammopathy, the suggested immunoglobulin deposition was present in only $3.75 \%$, a relatively low percentage of 160 eyes; however, the ophthalmologists have an essential role in detecting paraproteinemic keratopathy as an ophthalmic sign of the hematological disease, which should never be forgotten.

In our study, 12 eyes of 6 patients (7.50\%) with monoclonal gammopathy had glaucoma, 10 eyes $(6.25 \%)$ had open-angle glaucoma (OAG), and 2 eyes (1.25\%) had angle-closure glaucoma (ACG). Bertaud et al. [37] described the prevalence of OAG $3.05 \%$ in subjects between 40 and 80 years of age. Wright et al. [38] described the prevalence of ACG $0.02 \%$ in subjects with 40-49 years of age, and ACG prevalence increases to $0.95 \%$ in subjects older than 70 years. Between our controls, there were 4 eyes (4.65\%) with glaucoma. The proportion of glaucoma subjects was slightly higher in monoclonal gammopathy subjects, nevertheless, without a statistically significant difference, compared to our control population. Nevertheless, compared to literature data, both OAG and ACG prevalence was higher in our monoclonal gammopathy subjects as in the general population. Therefore, during an ophthalmic checkup, glaucoma screening should always be performed in monoclonal gammopathy subjects.

Although the percentage of epiretinal membrane was $6.25 \%$ among gammopathy subjects, this did not differ significantly from those in controls (2.33\%).

In plasma cell disorders, venous thromboembolism is a frequent complication due to hyperviscosity of the blood $[24,39]$. This is well displayed in ophthalmic findings in our patients, as we found 1 subject with previous central retinal artery occlusion and 1 with branch retinal vein occlusion. Both entities warrant regular ophthalmic checkups and ophthalmic treatment.

In addition to immunoglobulin deposition in the cornea and conjunctiva, other ophthalmic abnormalities have been reported in monoclonal gammopathy [18]. Some publications report the simultaneous appearance of monoclonal gammopathy and acute or chronic uveitis [19]. Moreover accumulation of monoclonal immunoglobulin crystals (kappa light chain type) in orbital fat and extraocular muscles, causing invasive masses (crystal storage histiocytosis) has been reported. Palpebral ecchymoses can occur due to vascular fragility secondary to amyloid. Munteanu has suggested a connection between Doyne's retinal dystrophy, benign monoclonal gammopathy, and the presence of corneal deposits [23]. Nevertheless, none of these entities were verified in our subjects, referring to the heterogeneity of diseases with monoclonal gammopathy, also concerning ocular signs and ocular comorbidities.

In summary, ocular surface disease and cataract are more common, and BCVA is worse in patients with monoclonal gammopathy than in age-matched controls. Therefore, and due to the potential ocular signs and comorbidities of monoclonal gammopathy, we suggest a regular, yearly ophthalmic checkup of these patients to improve their quality of life.

\section{Data Availability}

The data used to support the findings of this study are available from the corresponding author upon request.

\section{Conflicts of Interest}

The authors declare that they have no conflicts of interest.

\section{References}

[1] International Myeloma Working Group, "Criteria for the classification of monoclonal gammopathies, multiple myeloma and related disorders: a report of the International Myeloma Working Group," British Journal of Haematology, vol. 121, pp. 749-757, 2003.

[2] M. Ho, A. Patel, C. Y. Goh, M. Moscrin, L. Zhang, and G. Bianchi, "Changing paradigms in diagnosis and treatment of monoclonal gammopathy of undetermined significance (MGUS) and smoldering multiple myeloma (SMM)," Leukemia, vol. 34, no. 12, pp. 3111-3125, 2020. 
[3] Z. Nagy, "Multiple myeloma and other plasma cell dyscrasias [mielóma multiplex és egyéb plazmasejtes diszkráziák," Magyar Onkologia, vol. 60, pp. 154-163, 2016, in Hungarian.

[4] Z. Szemlaky and G. Mikala, "A waldenström-macroglobulinaemia és betegségre szabott kezelése," Orvosi Hetilap, vol. 158, no. 41, pp. 1604-1614, 2017, in Hungarian.

[5] O. Németh, B. Tapasztó, S. Tar et al., "Szaruhártya-lerakódások bizonytalan jelentőségü monoklonális gammopathiában. irodalmi áttekintés és esetbemutatás," Orvosi Hetilap, vol. 159, no. 39, pp. 1575-1583, 2018, in Hungarian.

[6] S. V. Rajkumar, "Evolving diagnostic criteria for multiple myeloma," Hematology ASH Education Program, vol. 2015, no. 1, pp. 272-278, 2015.

[7] O. Landgren, R. A. Kyle, R. M. Pfeiffer et al., "Monoclonal gammopathy of undetermined significance (MGUS) consistently precedes multiple myeloma: a prospective study," Blood, vol. 113, no. 22, pp. 5412-5417, 2009.

[8] R. A. Kyle, T. M. Therneau, S. V. Rajkumar et al., "Prevalence of monoclonal gammopathy of undetermined significance," The New England Journal of Medicine, vol. 354, pp. 1362-1369, 2016.

[9] S. H. Nasr, A. M. Valeri, L. D. Cornell et al., "Renal monoclonal immunoglobulin deposition disease: a report of 64 patients from a single institution," Clinical Journal of the American Society of Nephrology, vol. 7, no. 2, pp. 231-239, 2012.

[10] I. J. Sathick, M. E. Drosou, and N. Leung, "Myeloma light chain cast nephropathy, a review," Journal of Nephrology, vol. 32, no. 2, pp. 189-198, 2019.

[11] N. Steiner, A. Schwärzler, G. Göbel, W. Löscher, J. Wanschitz, and E. Gunsilius, "Are neurological complications of monoclonal gammopathy of undetermined significance underestimated?" Oncotarget, vol. 8, no. 3, pp. 5081-5091, 2017.

[12] S. Mathis, J. Franques, L. Richard, and J.-M. Vallat, "Monoclonal gammopathy of undeterminated significance and endoneurial IgG deposition: a case report," Medicine, vol. 95, no. 36, p. e4807, 2016.

[13] S. Ramchandren and R. A. Lewis, "An update on monoclonal gammopathy and neuropathy," Current Neurology and Neuroscience Reports, vol. 12, no. 1, pp. 102-110, 2012.

[14] M. A. Lichtman and S. R. Balderman, "Unusual manifestations of essential monoclonal gammopathy. II. simulation of the insulin autoimmune syndrome," Rambam Maimonides Medical Journal, vol. 6, no. 3, p. e0027, 2015.

[15] J. N. Buxbaum, E. M. Genega, P. Lazowski et al., "Infiltrative nonamyloidotic monoclonal immunoglobulin light chain cardiomyopathy: an underappreciated manifestation of plasma cell dyscrasias," Cardiology, vol. 93, no. 4, pp. 220-228, 2000.

[16] M. Erciyestepe, T. O. Tiryaki, İ. Yönal Hindilerden, G. Yeğen, and M. Nalçac1, "A case with hepatic involvement mimicking metastatic disease in multiple myeloma," Case Reports in Hematology, vol. 2020, Article ID 5738319, 4 pages, 2020.

[17] M. S. Daoud, J. A. Lust, R. A. Kyle, and M. R. Pittelkow, "Monoclonal gammopathies and associated skin disorders," Journal of the American Academy of Dermatology, vol. 40, no. 4, pp. 507-535, 1999.

[18] T. Milman, A. A. Kao, D. Chu et al., "Paraproteinemic keratopathy: the expanding diversity of clinical and pathologic manifestations," Ophthalmology, vol. 122, no. 9, pp. 1748-1756, 2015.

[19] C. C. Barr, H. Gelender, and R. L. Font, "Corneal crystalline deposits associated with dysproteinemia. report of two cases and review of the literature," Archives of Ophthalmology, vol. 98 , no. 5 , pp. $884-889,1980$.

[20] L. D. Ormerod, H. B. Collin, C. H. Dohlman, J. L. Craft, J. F. Desforges, and D. M. Albert, "Paraproteinemic crystalline keratopathy," Ophthalmology, vol. 95, no. 2, pp. 202-212, 1988.

[21] S. R. Balderman and M. A. Lichtman, "Unusual manifestations of monoclonal gammopathy: I. ocular disease," Rambam Maimonides Medical Journal, vol. 6, no. 3, p. e0026, 2015.

[22] S. J. Smith, M. W. Johnson, M. D. Ober, G. M. Comer, and B. D. Smith, "Maculopathy in patients with monoclonal gammopathy of undetermined significance," Ophthalmology Retina, vol. 4, no. 3, pp. 300-309, 2020.

[23] G. Munteanu, "Doyne's macular heredodystrophy and benign monoclonal gammopathy. genetic and pathogenetic correlations. [l'hérédodystrophie maculaire de doyne et la gammopathie monoclonale benign. corrélations génétiques et pathogéniques," Journal Français D’Ophtalmologie, vol. 3, pp. 753-758, 1980, in French.

[24] E. I. Agorogiannis and V. Kotamarthi, "Paraproteinemia and central retinal vein occlusion," Hippokratia, vol. 19, p. 92, 2015.

[25] T. Nakazawa, K. Yamaguchi, Y. Nakagawa et al., "Two cases of orbital myositis with monoclonal gammopathy of undetermined significance," Nippon Ganka Gakkai Zasshi, vol. 108, pp. 110-117, 2004.

[26] D. C. Garibaldi, J. Gottsch, Z. de la Cruz, M. Haas, and W. R. Green, "Immunotactoid keratopathy: a clinicopathologic case report and a review of reports of corneal involvement in systemic paraproteinemias," Survey of Ophthalmology, vol. 50, no. 1, pp. 61-80, 2005.

[27] W. Lisch, P. Saikia, S. Pitz et al., "Chameleon-like appearance of immunotactoid keratopathy," Cornea, vol. 31, no. 1, pp. 55-58, 2012.

[28] G. Varga, G. Mikala, L. Váróczy, and Á. Illés, “A myeloma multiplex megközelítése Magyarországon 2016-ban," Orvosi Hetilap, vol. 157, no. 4, pp. 123-137, 2016, in Hungarian.

[29] "The epidemiology of dry eye disease: report of the epidemiology subcommittee of the international dry eye workshop (2007)," The Ocular Surface, vol. 5, pp. 93-107, 2007.

[30] R. Dana, J. L. Bradley, A. Guerin et al., "Estimated prevalence and incidence of dry eye disease based on coding analysis of a large, all-age United States health care system," American Journal of Ophthalmology, vol. 202, pp. 47-54, 2019.

[31] A. L. Kunkler, E. M. Binkley, D. Mantopoulos et al., "Known and novel ocular toxicities of biologics, targeted agents, and traditional chemotherapeutics," Graefe's Archive for Clinical and Experimental Ophthalmology, vol. 257, no. 8, pp. 17711781, 2019.

[32] A. Fel, E. Aslangul, and C. Le Jeunne, "Indications et complications des corticoïdes en ophtalmologie," La Presse Médicale, vol. 41, no. 4, pp. 414-421, 2012, in French.

[33] X. Chen, D. Y. Zhou, J. Shen et al., "Prevalence and risk factors on age-related cataract and surgery in adults over 50 years old in Binhu District, Wuxi, China," International Journal of Ophthalmology, vol. 13, pp. 445-451, 2020.

[34] T. H. Rim, M. J. Kang, M. Choi, K. Y. Seo, and S. S. Kim, “Tenyear incidence and prevalence of clinically diagnosed blepharitis in South Korea: a nationwide population-based cohort study," Clinical \& Experimental Ophthalmology, vol. 45, no. 5, pp. 448-454, 2017.

[35] J.-G. Gao, J. Chen, Y. Tang, and D. N. Chen, "Prevalence of meibomian gland dysfunction in staffs and faculty members of a Chinese university," International Journal of Ophthalmology, vol. 13, no. 10, pp. 1667-1670, 2020. 
[36] C. Liisborg, M. K. Nielsen, H. C. Hasselbalch, and T. L. Sørensen, "Patients with myeloproliferative neoplasms and high levels of systemic inflammation develop age-related macular degeneration," EClinicalMedicine, vol. 26, p. 100526, 2020.

[37] S. Bertaud, V. Aragno, C. Baudouin, and A. Labbé, "Le glaucome primitif à angle ouvert," La Revue de Médecine Interne, vol. 40, no. 7, pp. 445-452, 2019, in French.

[38] C. Wright, M. A. Tawfik, M. Waisbourd, and L. J. Katz, "Primary angle-closure glaucoma: an update," Acta Ophthalmologica, vol. 94, no. 3, pp. 217-225, 2016.

[39] S. Y. Kristinsson, T. R. Fears, G. Gridley et al., "Deep vein thrombosis after monoclonal gammopathy of undetermined significance and multiple myeloma," Blood, vol. 112, no. 9, pp. 3582-3586, 2008. 